\title{
Dynamical study of the water penetration process into a cellulose acetate film studied by coherent anti-Stokes Raman scattering (CARS) microspectroscopy
}

Rie Fujisawa ${ }^{1}$, Tomoya Ohno ${ }^{2}$, Junya F. Kaneyasu ${ }^{2}$, Philippe Leproux ${ }^{3}$, Vincent Couderc ${ }^{3}$, Hiroshi Kita ${ }^{1}$, Hideaki Kano ${ }^{2,4,5^{*}}$

${ }^{1}$ Konicaminolta Inc., Hachioji, Tokyo, Japan

${ }^{2}$ Department of Applied Physics, Graduate School of Pure and Applied Sciences, University of Tsukuba, 1-1-1 Tennodai, Tsukuba, Ibaraki 305-8573, Japan

${ }^{3}$ Institut de Recherche XLIM, UMR CNRS No. 7252, 123 avenue Albert Thomas, 87060 Limoges CEDEX, France

${ }^{4}$ Institute of Applied Physics, University of Tsukuba, 1-1-1 Tennodai, Tsukuba, Ibaraki 305-8573, Japan

${ }^{5}$ Tsukuba Research Center for Interdisciplinary Materials Science (TIMS), University of Tsukuba, 1-1-1 Tennodai, Tsukuba, Ibaraki 305-8571, Japan

*E-mail: hkano@bk.tsukuba.ac.jp

\section{ABSTRACT}

The penetration process of water into a cellulose acetate (CA) film was traced in real time by coherent anti-Stokes Raman scattering (CARS) microspectroscopy. The $\mathrm{C}=\mathrm{O}$ stretch mode was red-shifted due to hydrogen-bond formation. We also found that two Raman bands at $1605 \mathrm{~cm}^{-1}$ and $1665 \mathrm{~cm}^{-1}$ emerged only in the early stage of the water penetration process. Based on the combined analysis of the experimental and computational studies, these bands at $1605 \mathrm{~cm}^{-1}$ and $1665 \mathrm{~cm}^{-1}$ were assigned as the $\mathrm{OH}$ bend mode due to hydrogen-bonded penetrated water and hydrogen-bonded $\mathrm{OH}$ groups in pyranose rings, respectively. 


\section{Introduction}

Cellulose can be obtained from natural resources such as wood and grass, and is one of the most abundant organic molecules in the world. Recently, biomass materials such as cellulose have attracted a lot of attention as alternatives of fossil in order to establish fossil-free sustained society. Besides energy issues, cellulose is also known as one of the most useful industrial materials extracted from biomass. It can be easily modified by simple chemical reactions. Various kinds of functional materials have been developed so far using cellulose. Celluloid was one of the most famous chemically modified celluloses, and was frequently used for a past as very useful resins. However, because of its high combustibility, celluloid is no longer used. Instead of celluloid, cellulose acetate (CA) has attracted much attention for industrial application. One of the most useful applications of CAs is fabrication of functional optical films in liquid crystal displays (LCDs). In LCDs, several types of functional optical films such as anti-reflection films, phase-retardation films, and polarization films are used. Depending on the optical properties for these films, fabrication processes and degree of substitution are different. The request on specifications of industrial optical films has been severe to have various properties such as specific refraction index, high heat resistance, high solvent resistance, high barrier property to gas, high mechanical strength, and high transparency. Therefore, it is necessary to explore new kinds of polymer materials with multiple functionalities.

So far, resins such as polyethylene (PE), polyethylene terephthalate (PET), polycarbonate $(\mathrm{PC})$, cyclo-olefin polymer (COP), and cellulose derivatives such as $\mathrm{CA}$ have been used for LCDs. Among them, CA is one of the best materials in the view points of adjustable refractive index, high heat resistance and high transparency. Another advantage of CAs is good stretch property and capability of film fabrication with large area and with uniform thickness. Although there are many great advantages on CA films, they show medium-level water absorbability, which might deteriorate the quality of films and prevent 
CA films from long-term use. Concerning the application to a LCD film, water absorbability is not critical, because the films are packaged inside the glasses, which perfectly block water penetration. For universal applications of CAs, however, the development of waterproof CA is highly desirable, because it is directly applicable to various functional films such as decorate films, screen films, and window films. In order to design such waterproof CAs, we need to understand detailed mechanism on water absorbability of CA itself. Since CA in film is in amorphous phase, vibrational spectroscopy such as IR and Raman spectroscopy should be one of the most suitable methods, and several studies have been reported on the interaction between water and cellulose film [1-11]. However, there is no dynamical study using Raman spectroscopy because of the limited acquisition speed. In the present study, we used coherent anti-Stokes Raman scattering (CARS) microspectroscopy in order to investigate the dynamical process of water penetration to $\mathrm{CA}$ films. Thanks to the ultrabroadband spectral coverage of the multiplex CARS system, the whole fundamental modes in the fingerprint region can be detected simultaneously with temporal resolution with 50 msec.

In the CARS process, two laser pulses with different angular frequencies (referred to as $\omega_{1}$ and $\omega_{2}$ pulses or pump and Stokes pulses) are used. If the angular frequency difference of these two incident pulses, namely $\omega_{1}-\omega_{2}$, coincides with that of the vibrational mode of the sample molecule, $\Omega$, the intense and unidirectional radiation with an angular frequency of $2 \omega_{1}-\omega_{2}$ takes place due to a nonlinear Raman process. This is called the CARS radiation. With the use of supercontinuum (SC) as $\omega_{2}$ pulses, we can obtain multiplex CARS spectra $[12-25]$

\section{Experimental}

CA resin with degree of substitution (DS) of 2.4 was obtained from Eastman Chemical 
Company. CA film was prepared as following method. CA resin was dissolved in methylene chloride and ethanol and the solution was coated by using a \#14 wire bar coater on the glass plate, and dried at room temperature for 5 minutes and further at $120^{\circ} \mathrm{C}$ for 20 minutes. The CA film was sandwiched between a slide glass and a cover glass with silicone adhesive. The film was cut into two pieces ( $5 \mathrm{~mm} \times 15 \mathrm{~mm}$ ) and was put separately as shown in the inset of Fig. 1. A drop of water was introduced from the edge of the sample, and was penetrated through the duct between two films.

The multiplex CARS system was developed by our group and has been already reported elsewhere [12-25]. A Q-switched microchip Nd:YAG laser was used as a light source. The center wavelength, temporal duration, and repetition rate were $1064 \mathrm{~nm}, 800 \mathrm{ps}$, and $33 \mathrm{kHz}$, respectively. A part of the output of the master laser was used for $\omega_{1}$ laser (pump laser). The other was introduced into a photonic crystal fiber (PCF) to generate supercontinuum (SC). Ultrabroadband SC ranging from visible to NIR was used as $\omega_{2}$ laser. After removing spectral components shorter than $1064 \mathrm{~nm}$ from the SC using a long-pass filter, $\omega_{1}$ and $\omega_{2}$ laser radiations were superimposed by a notch filter, and then introduced into a modified inverted microscope (Nikon: ECLIPSE Ti). Incident laser radiations were tightly focused onto a sample by the first objective lens. The sample was placed upon a piezo electric stage (PZT, Mad City Lab: Nano-LP200) for position selection. The CARS signal was collected by the second objective lens, and then introduced into a spectrograph (Princeton Instruments: LS785). Finally, the CARS signal was detected by a CCD camera (Princeton Instruments: PIXIS 100BR). Exposure time was $50 \mathrm{msec}$ per pixel. For data analysis, we employ the maximum entropy method (MEM) to extract the amplitude and phase of vibrational resonances from the complicated CARS spectra that we observe $[24,25]$. The MEM does not require any a priori information about the vibrational bands but still is able to retrieve the phase information on the third-order nonlinear susceptibility of the CARS process, $\chi^{(3)}$. The imaginary part of $\chi^{(3)}, \operatorname{Im}\left[\chi^{(3)}\right]$, corresponds to a spontaneous Raman 
spectrum, whose intensity is proportional to molecular concentration.

\section{Results and discussion}

First, we measured water content of $\mathrm{CA}(\mathrm{DS}=2.4)$ films before and after water penetration by measuring weight loss on drying. The water content before and after water penetration were measured to be $2.4 \%$ and $13.6 \%$ (weight $\%$ ), respectively.

Next, we measured the spectral profile of a CA film before water penetration. As discussed, the water content was $2.4 \%$ in the atmospheric condition, Figure $1 \operatorname{shows} \operatorname{Im}\left[\chi^{(3)}\right]$ spectrum of a CA film in the fingerprint region. The result agrees well with the reported Raman spectrum of CA [26-31]. The assignment is listed in Table 1.

We then performed real-time observation of water penetration process of a CA film. Figure 2 shows the time-resolved CARS spectra. At $0 \mathrm{sec}$, we started to record the CARS spectra before loading water. With the time interval of $50 \mathrm{msec}$, we continued the measurement upto $600 \mathrm{sec}$. Water was loaded around $50 \mathrm{sec}$. It should be noted that the sample stage was fixed at the same position.

The hydrogen bond formation was observed profoundly by the spectral change of the $\mathrm{C}=\mathrm{O}$ bond. Figures $3(\mathrm{a})$ and (b) show the close up spectral profiles of $\mathrm{C}=\mathrm{O}$ bond around $1735 \mathrm{~cm}^{-1}$ before (5 sec; (a)) and sufficiently after $(600 \mathrm{sec}$; (b)) water penetration. These spectra were calculated from the results in Fig. 2 by averaging 10 spectra. The $\mathrm{C}=\mathrm{O}$ band at $1735 \mathrm{~cm}^{-1}$ was red-shifted to $1732 \mathrm{~cm}^{-1}$ through water penetration. This red shift agrees well with the previous study [3]. It was interpreted as the result of hydrogen bond formation between carbonyl groups and penetrated water molecules. In the present study, we found that the band shape of $\mathrm{C}=\mathrm{O}$ bond was asymmetric. We therefore fitted this band using the sum of three Gaussian functions. Figures 3(a) and (b) show the fitted results of CA films before (a) and after (b) water penetration. The peak positions of three bands in Fig. 3(a) were determined to be $1731 \pm 0.2,1743 \pm 0.4$ and $1791 \pm 0.7 \mathrm{~cm}^{-1}$. On the other hand, in Fig. 
3(b), the peak positions of three bands in Fig. 3(b) were determined to be $1729 \pm 0.7$, $1740 \pm 0.3$, and $1789 \pm 0.5 \mathrm{~cm}^{-1}$. It should be noticed that all three Gaussian band are red-shifted.

Similar spectral analysis was carried out for real-time traced CARS spectra in Fig. 2. Namely, we fitted the $\mathrm{C}=\mathrm{O}$ band using the sum of three Gaussian bands with free amplitudes, peak positions, but fixed bandwidths. Figure 3(c) show the fitted results of the dynamical behavior of the $\mathrm{C}=\mathrm{O}$ band. Figures 3(c) (top) corresponds to the temporal profiles of the $\mathrm{C}=\mathrm{O}$ peak positions, which was calculated as the weighted mean of the frequencies with their amplitudes as the weights. On the other hand, Fig. 3(c) (bottom) corresponds to the temporal profiles of the $\mathrm{C}=\mathrm{O}$ band intensity, which was calculated as the area sum of three bands. The signal intensity of the $\mathrm{C}=\mathrm{O}$ band was dropped just after loading water around 50 sec. It is probably caused by some mechanical drifts due to water penetration. Although the signal intensity was decreased, the band shifts were clearly observed throughout the penetration process. The spectral shift at the band of $1743 \mathrm{~cm}^{-1}$ was fitted by an exponential function, and the time constant was determined to be $140 \pm 2 \mathrm{sec}$.

Interestingly, we found that the new bands in the region of $1600-1700 \mathrm{~cm}^{-1}$ emerged only in the early stage of the water penetration process. It was observed in particular around 50 sec in Fig. 2. The close-up spectral profile between 1570 and $1710 \mathrm{~cm}^{-1}$ at $55 \mathrm{sec}$ is indicated in Fig. 4(a). There are mainly two bands. We performed fitting of these two bands using the one and two Gaussian functions for the bands around 1606 and $1663 \mathrm{~cm}^{-1}$, respectively. The peak position at the former band was determined to be $1606 \pm 0.3 \mathrm{~cm}^{-1}$. On the other hand, the latter band around $1663 \mathrm{~cm}^{-1}$ is decomposed into the two bands at the peak positions of $1655 \pm 0.9$ and $1665 \pm 0.3 \mathrm{~cm}^{-1}$. With the help of the fitted parameter, we analyzed real-time traced CARS spectra in the region of $1570-1710 \mathrm{~cm}^{-1}$. Figure $4(\mathrm{~b})$ shows the dynamical behavior of the two bands. In order to correct the apparent signal decrease around $50 \mathrm{sec}$, which is mainly caused by a mechanical drift of the sample due to water penetration, 
we have divided the transient curve with that of $\mathrm{C}=\mathrm{O}$ stretch mode (Fig. 3(c)).

As shown in Fig. 4(b), both of the two bands show almost instantaneous response. The temporal profiles are fitted with the function of the convolution of the Gaussian function and an exponential function. The decay time was determined to be $20 \pm 5 \mathrm{sec}$. This suggests that the observed Raman-active modes are tentatively observed only in the early stage of the water penetration into CA film.

In order to elucidate the origin of the bands, we performed DFT calculation. We used the CA tetramer model with two water molecules. Two terminal groups of the CA tetramer were replaced by $-\mathrm{OCH}_{3}$. Using Gaussian 09 Revision D.01 [34] with the basis set of B3LYP/6-31G $(\mathrm{d}, \mathrm{p})$, geometry optimization and frequency calculation was performed. Figure 5 shows the optimized geometry, in which one of the water molecules is located around carbonyl group and hydroxyl group of the pyranose ring.

The experimental and calculated results are shown in Figs. 6(a) and (b). Calculated result reproduced well the overall spectral profile around $1735 \mathrm{~cm}^{-1}$ due to $\mathrm{C}=\mathrm{O}$ stretch vibrational mode and the two bands around 1606 and $1665 \mathrm{~cm}^{-1}$ which appeared only in the early stage of the water penetration process (Fig. 6(a)). The peak positions of two bands are $1594 \mathrm{~cm}^{-1}$ and $1684 \mathrm{~cm}^{-1}$, which are close to the experimental results $\left(1606\right.$ and $\left.1665 \mathrm{~cm}^{-1}\right)$. Based on the calculation, these bands at 1594 and $1684 \mathrm{~cm}^{-1}$ are assigned as $\mathrm{OH}$ bend mode due to hydrogen-bonded penetrated water and hydrogen-bonded $\mathrm{OH}$ groups in pyranose rings, respectively. Although the experimental and calculative studies revealed that the transient bands between 1580 and $1700 \mathrm{~cm}^{-1}$ correspond well to those due to the $\mathrm{OH}$ bend mode, the instantaneous response is still unclear. Further study should be needed to elucidate the origin and mechanism of instantaneous response of these $\mathrm{O}-\mathrm{H}$ bend modes.

\section{Conclusion}

In conclusion, we traced dynamic process of water penetration into a CA film using 
CARS microspectroscopy. Water penetration results in the red shift of $\mathrm{C}=\mathrm{O}$ band from 1734 $\mathrm{cm}^{-1}$ to $1731 \mathrm{~cm}^{-1}$, which reproduced well with the reported study. Owing to the high temporal resolution, we also found that the band possibly due to the $\mathrm{OH}$ bend mode emerged only in the early stage of the water penetration process. This finding should be useful to develop waterproof CA. By monitoring of this band and by suppressing the emergence of this band in the water penetration process, we can improve water-resistant of film surface.

\section{Acknowledgments}

We acknowledge the support of Konica Minolta Science and Technology Foundation. The authors are grateful for the help on calculation of Tatsuya Hattori, and the helpful comments of Yuji Nishikawa and Hiroto Itoh. The authors thank the LEUKOS company for technical support with the dual-output supercontinuum light source. The authors gratefully acknowledge J. Ukon, UKON CRAFT SCIENCE, Ltd. for assisting with a fruitful collaboration between Japanese and French labs.

\section{References}

1) D. Cristina R., M. J. Rosa, M. N. de Pinho, J. Membr. Sci. 138 (1998) 259.

2) S. O. Han, J. H. Youk, K. D. Min, Y. O. Kang, W. H. Park, Mater. Lett. 62 (2008) 759.

3) A. Watanabe, S. Morita, S. Kokot, M. Matsubara, K. Fukai, Y. Ozaki, J. Mol. Struct. 799 (2006) 102.

4) A. Watanabe, S. Morita, Y. Ozaki, Biomacromolecules 7 (2006) 3164.

5) A. Watanabe, S. Morita, S. Kokot, M. Matsubara, K. Fukai, Y. Ozaki, J. Mol. Struct. 799 (2006) 102.

6) S. Morita, M. Tanaka, Y. Ozaki, Langumuir 23 (2007) 3750. 
7) J. R. Scherer, G. F. Bailey, J. Membr. Sci. 13 (1983) 43.

8) J. R. Scherer, G. F. Bailey, S. Kint, R. Young, P. Malladi, B. Bolton, J. Phys. Chem. 89 (1985) 312.

9) G. Arthanareeswaran, P. Thanikaivelan, K. Srinivasn, D. Mohan, M. Rajendran, Eur. Polym. J. 40 (2004) 2153.

10) K. Kowsaka, K. Okajima, K. Kamide, Polym. J. 20 (1998) 827.

11) T. Iwata, J. Azuma, K. Okamura, F. Tanaka, Sen-i Gakkaishi 47 (1991) 379.

12) M. Okuno, H. Kano, P. Leproux, V. Couderc, J. P. Day, M. Bonn, H. Hamaguchi, Angew. Chem., Int. Ed. 49 (2010) 6773.

13) M. D. Duncan, J. Reintjes, T. J. Manuccia, Opt. Lett. 7 (1982) 350.

14) A. Zumbusch, G. R. Holtom, X. S. Xie, Phy. Rev. Lett. 82 (1999) 4142.

15) M. Hashimoto, T. Araki, S. Kawata, Opt. Lett. 25 (2000) 1768.

16) T. W. Kee, M. T. Cicerone, Opt. Lett. 29 (2004) 2701.

17) J. X. Cheng, X. S. Xie, J. Phys. Chem. B 108 (2004) 827.

18) H. Kano, H. Hamaguchi, Appl. Phys. Lett. 86 (2005) 121113.

19) G. I. Petrov, V. Yakovlev, Opt. Express 13 (2005) 1299.

20) A. Volkmer, Journal of Physics D: Appl. Phys. 38, (2005) R59.

21) C. L. Evans, X. S. Xie, Annu. Rev. Anal. Chem. 1 (2008) 883.

22) J. P. Day, K. F. Domke, G. Rago, H. Kano, H. Hamaguchi, E. M. Vartiainen, M. Bonn, J. Phys. Chem. B 115 (2011) 7713.

23) J. X. Cheng, S. X. Xiaoliang, eds. Coherent Raman Scattering Microscopy, CRC Press, 2012.

24) E. M. Vartiainen, K. E. Peiponen, T. Tsuboi, J Opt Soc Am. B-Opt. Phys 7 (1990) 722.

25) E. M. Vartiainen, H. A. Rinia, M. Muller, M. Bonn, Opt. Express 14 (2006) 3622.

26) K. Zhang, A. Feldner, S. Fischer, Cellulose 18 (2011) 995.

27) B. H. Holder, Characterization of Starch by Vibrational Spectroscopy. 2012. 
28) K. Schenzel, S. Fischer, Cellulose 8 (2001) 49.

29) D. L. VanderHart, J. A. Hyatt, R. H. Atalla, V. C. Tirumalai, Macromolecules 29 (1996) 730.

30) S. P. Firsov, R. G. Zhbankov, J. Appl. Spectrosc. 37 (1982) 940.

31) J. H. Wiley, R. H. Atalla, Carbohydr. Res. 160 (1987) 113.

32) D. Ostrovskii, A. L. Kjøniksen, B. Nyström, L. M. Torell, Macromolecules 32 (1999) 1534.

33) H. G. M. Edwards, D. W. Farwell, D. Webster, Spectrochimica Acta Part A. Mol. Biomol. Spectrosc. 53 (1997) 2383.

34) M. J. Frisch, G. W. Trucks, H. B. Schlegel, G. E. Scuseria, M. A. Robb, J. R. Cheeseman, G. Scalmani, V. Barone, B. Mennucci, G. A. Petersson, H. Nakatsuji, M. Caricato, X. Li, H. P. Hratchian, A. F. Izmaylov, J. Bloino, G. Zheng, J. L. Sonnenberg, M. Hada, M. Ehara, K. Toyota, R. Fukuda, J. Hasegawa, M. Ishida, T. Nakajima, Y. Honda, O. Kitao, H. Nakai, T. Vreven, J. A. Montgomery, Jr., J. E. Peralta, F. Ogliaro, M. Bearpark, J. J. Heyd, E. Brothers, K. N. Kudin, V. N. Staroverov, R. Kobayashi, J. Normand, K. Raghavachari, A. Rendell, J. C. Burant, S. S. Iyengar, J. Tomasi, M. Cossi, N. Rega, J. M. Millam, M. Klene, J. E. Knox, J. B. Cross, V. Bakken, C. Adamo, J. Jaramillo, R. Gomperts, R. E. Stratmann, O. Yazyev, A. J. Austin, R. Cammi, C. Pomelli, J. W. Ochterski, R. L. Martin, K. Morokuma, V. G. Zakrzewski, G. A. Voth, P. Salvador, J. J. Dannenberg, S. Dapprich, A. D. Daniels, Ö. Farkas, J. B. Foresman, J. V. Ortiz, J. Cioslowski, and D. J. Fox, Gaussian, Inc., Wallingford CT, 2009. 


\section{Figure Captions}

Table 1. Raman bands and their assignments of cellulose acetate film

Fig. 1. $\operatorname{Im}\left[\chi^{(3)}\right]$ spectra of CA film in the fingerprint region before water penetration. The peak positions are indicated. The inset shows the schematic of the sample.

Fig. 2. Real-time traced $\operatorname{Im}\left[\chi^{(3)}\right]$ spectra of CA film. Each spectrum was averaged within $500 \mathrm{msec}$ (10 points), and displayed in every 50 seconds. Baseline subtraction has been performed. $0 \mathrm{sec}$ corresponds to the time before introducing water. The penetration of water takes place around $50 \mathrm{sec}$.

Fig. 3. Spectral profiles of $\operatorname{Im}\left[\chi^{(3)}\right]$ at $\mathrm{C}=\mathrm{O}$ band before (a) and after (b) the water penetration. The spectral profiles were averaged within $500 \mathrm{msec}(10$ points) at $0 \mathrm{sec}$ (a) and $600 \mathrm{sec}(\mathrm{b})$. Fitted results are also indicated. We used three Gaussian functions whose peak positions of $1731 \mathrm{~cm}^{-1}$ (dotted) $1743 \mathrm{~cm}^{-1}$ (dashed) and $1791 \mathrm{~cm}^{-1}$ (dashed-dotted) for (a) and $1729 \pm 0.7$ $\mathrm{cm}^{-1}$ (dotted), $1740 \mathrm{~cm}^{-1}$ (dashed), and $1789 \mathrm{~cm}^{-1}$ (dashed-dotted) for (b); (c) Temporal profiles of the peak position and integrated band intensity of the $\mathrm{C}=\mathrm{O}$ bond. The $\mathrm{C}=\mathrm{O}$ peak positions was calculated as the weighted mean of the frequencies with their amplitudes as the weights. The $\mathrm{C}=\mathrm{O}$ band intensity was calculated as the sum of three bands.

Fig. 4 (a) Spectral profile of $\operatorname{Im}\left[\chi^{(3)}\right]$ around $1570-1710 \mathrm{~cm}^{-1}$ at $55 \mathrm{sec}$, which was averaged within $500 \mathrm{msec}$ (10 points). Negative baseline is due to the retrieval of MEM 
procedure. Fitted result is also shown. We used three Gaussian functions whose peak positions of $1606 \mathrm{~cm}^{-1}$ (dotted), $1655 \mathrm{~cm}^{-1}$ (dashed), and $1665 \mathrm{~cm}^{-1}$ (dashed-dotted). (b) Temporal profiles of the integrated band intensity around $1606 \mathrm{~cm}^{-1}$ (dotted) and $1663 \mathrm{~cm}^{-1}$ (solid). Fitted results are also shown. The temporal profiles were fitted with the function of the convolution of the Gaussian function and the exponential function.

Fig. 5 The optimized geometry calculated by Gaussian 09 Revision D.01 with the basis set of B3LYP/6-31G(d,p). Black, gray, white balls represent carbon oxygen hydrogen atoms, respectively. The hydrogen-bonded water molecule is marked by the broken circle.

Fig. 6 Spectral profile of $\operatorname{Im}\left[\chi^{(3)}\right]$ around $1580-1800 \mathrm{~cm}^{-1}$ (a) and a result of DFT calculation (b). 
Table 1.

\begin{tabular}{|c|c|}
\hline Raman bands & Assignment \\
\hline $1740 \mathrm{~cm}^{-1}$ & stretch vibrational mode of $\mathrm{C}=\mathrm{O}$ bonds in acetyl groups \\
\hline $1,434 \mathrm{~cm}^{-1}$ & deformation vibrational mode of $\mathrm{CH}_{3}$-groups within acetyl groups \\
\hline $1376 \mathrm{~cm}^{-1}$ & various deformation vibrational mode of cellulose backbones \\
\hline $1160 \mathrm{~cm}^{-1}$ & asymmetric vibrational mode of $\mathrm{C}-\mathrm{C}$ and $\mathrm{C}-\mathrm{O}$ bonds in cellulose (ring \\
\hline $1124 \mathrm{~cm}^{-1}$ & orrages between nelgnoormg pyranose \\
\hline $1080 \mathrm{~cm}^{-1}$ & symmetric ring breathing mode of C-O-C group \\
\hline $917 \mathrm{~cm}^{-1}$ & C-O-C, C-O-H bend, C-O stretch \\
\hline $844 \mathrm{~cm}^{-1}$ & $\mathrm{C}-\mathrm{C}-\mathrm{H}, \mathrm{C}-\mathrm{O}-\mathrm{C}$ bend \\
\hline
\end{tabular}


References

[29]

[30]

[28]

[28]

[32]

[28], [33]

[27]

[27] 
Fig. 1.

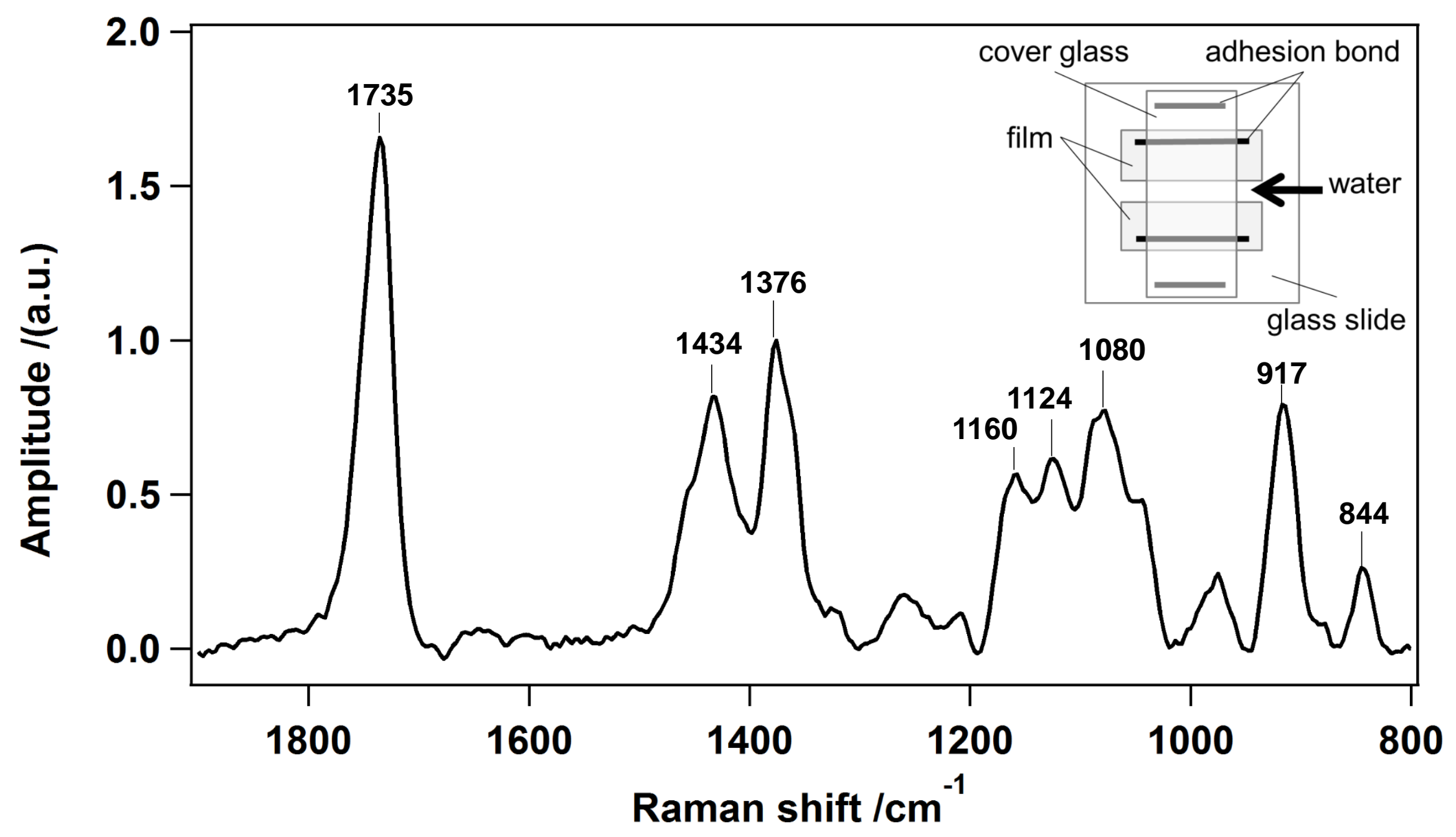


Fig. 2.

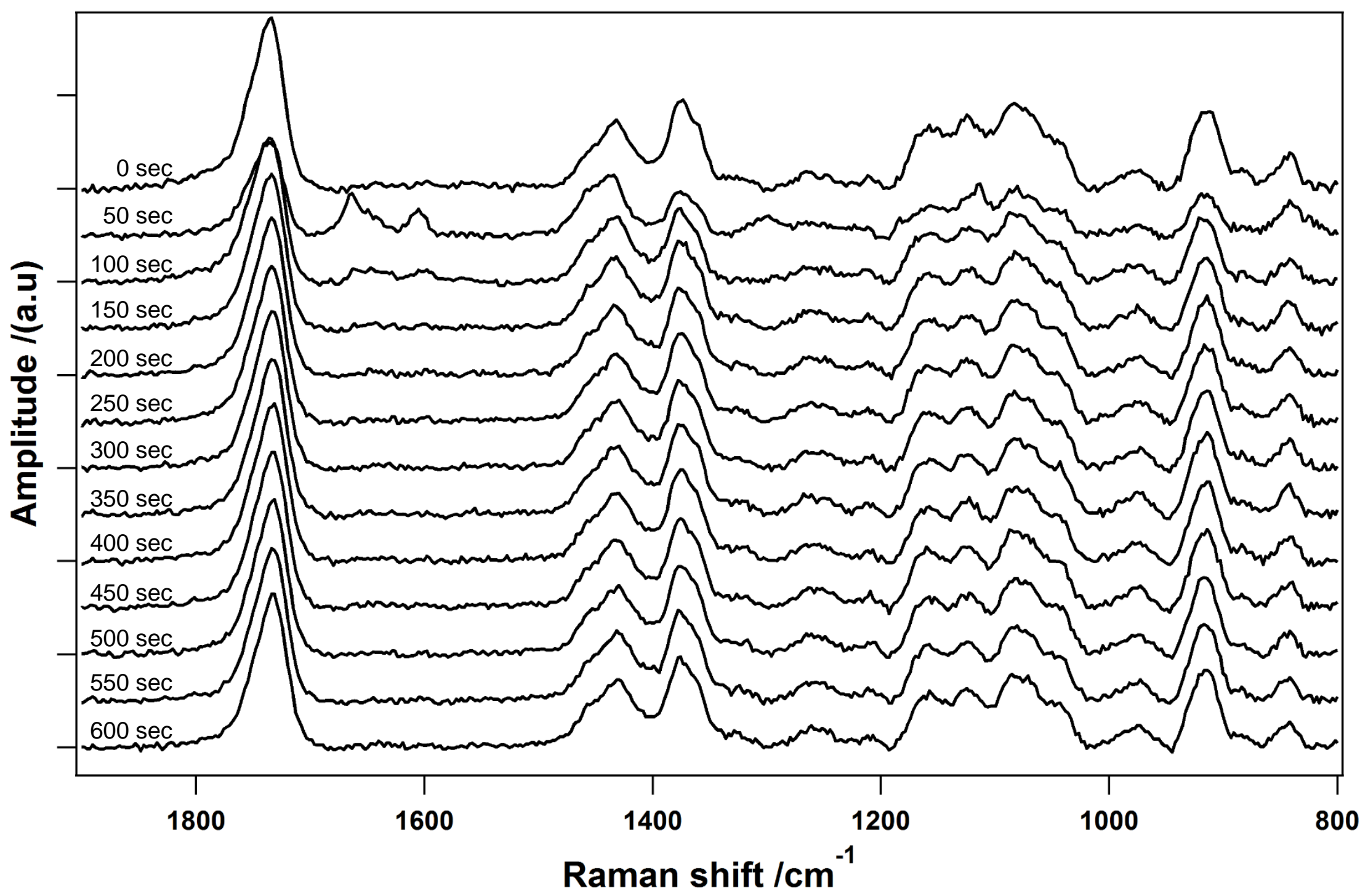




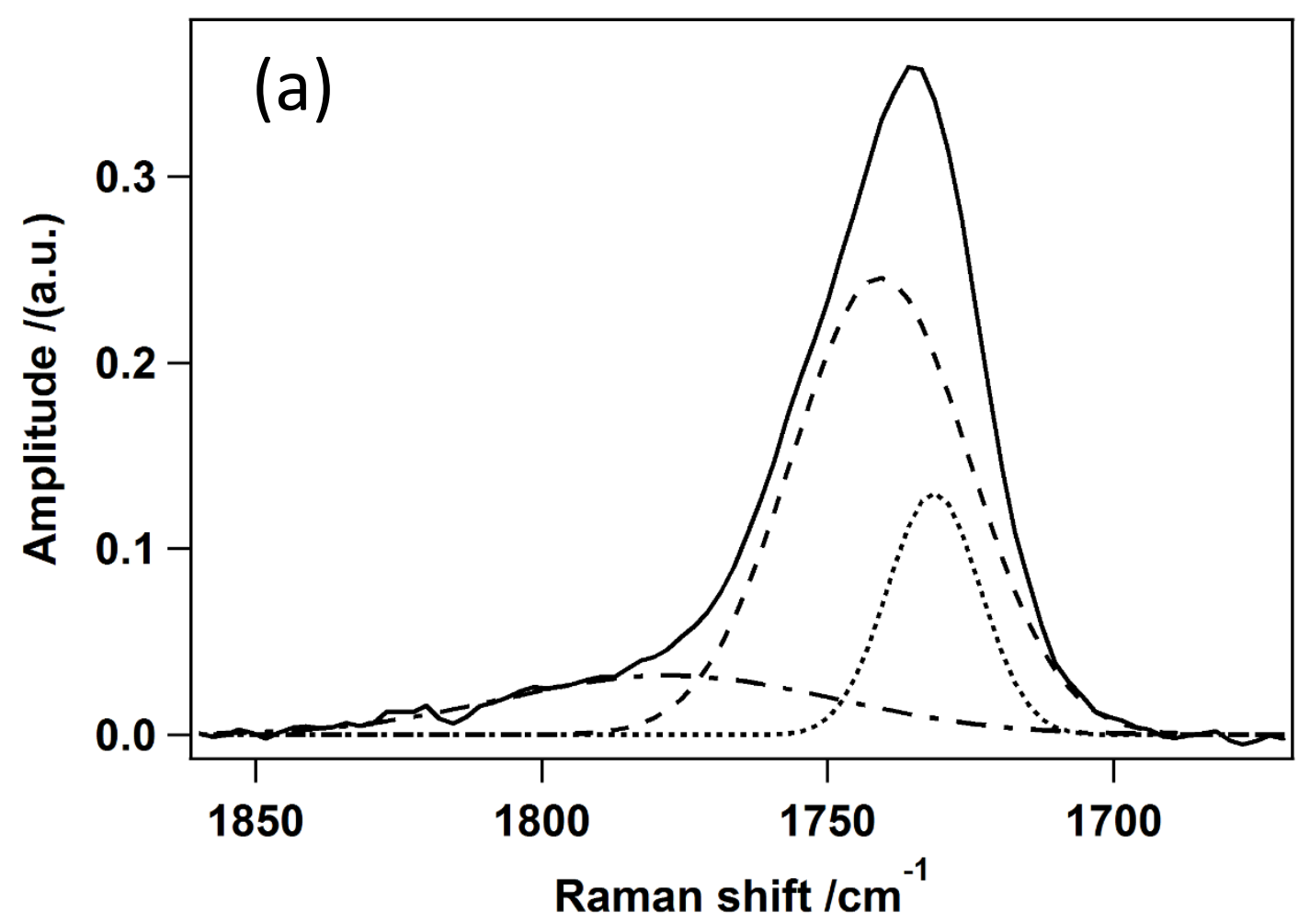

Fig. 3.
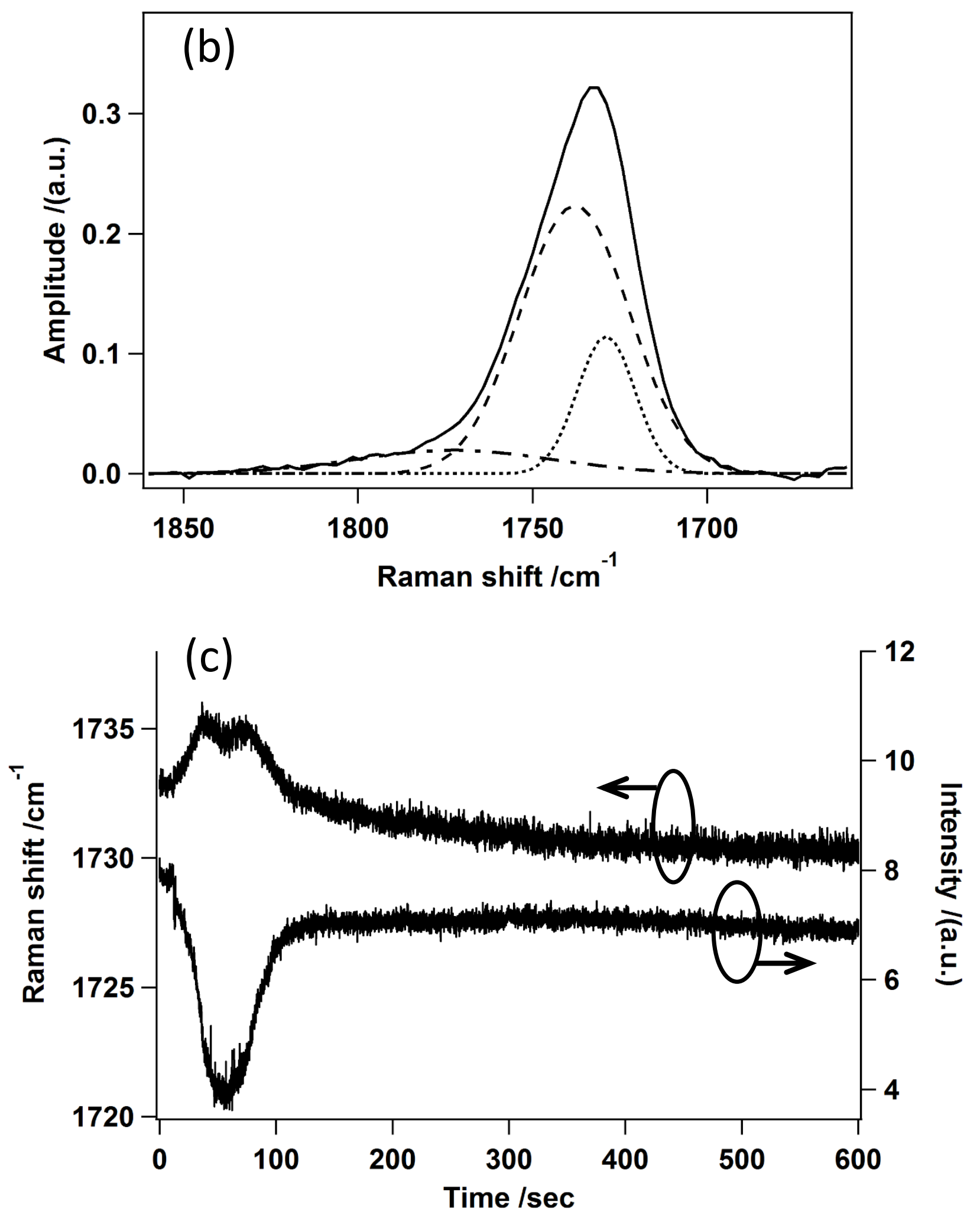


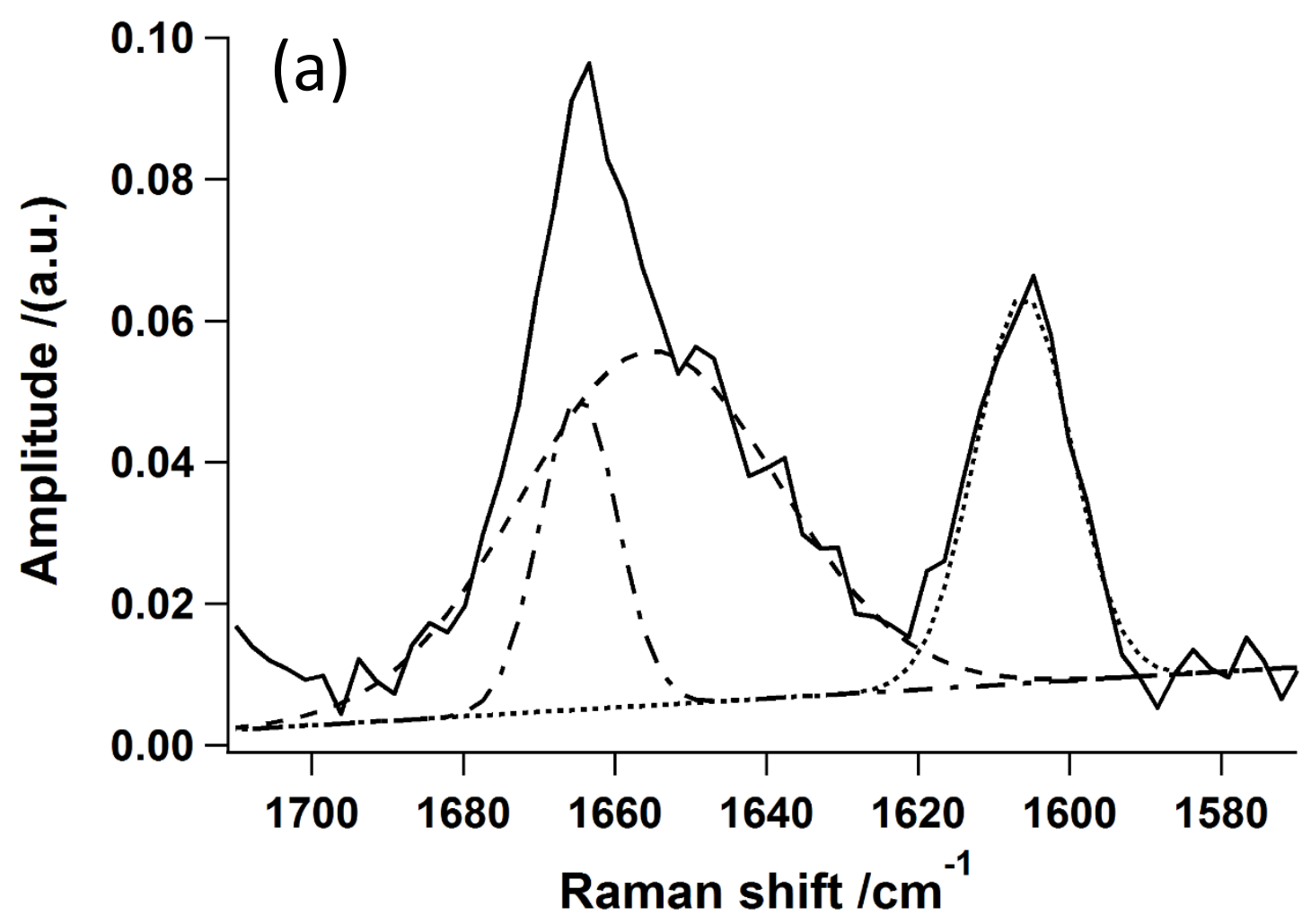

Fig. 4.

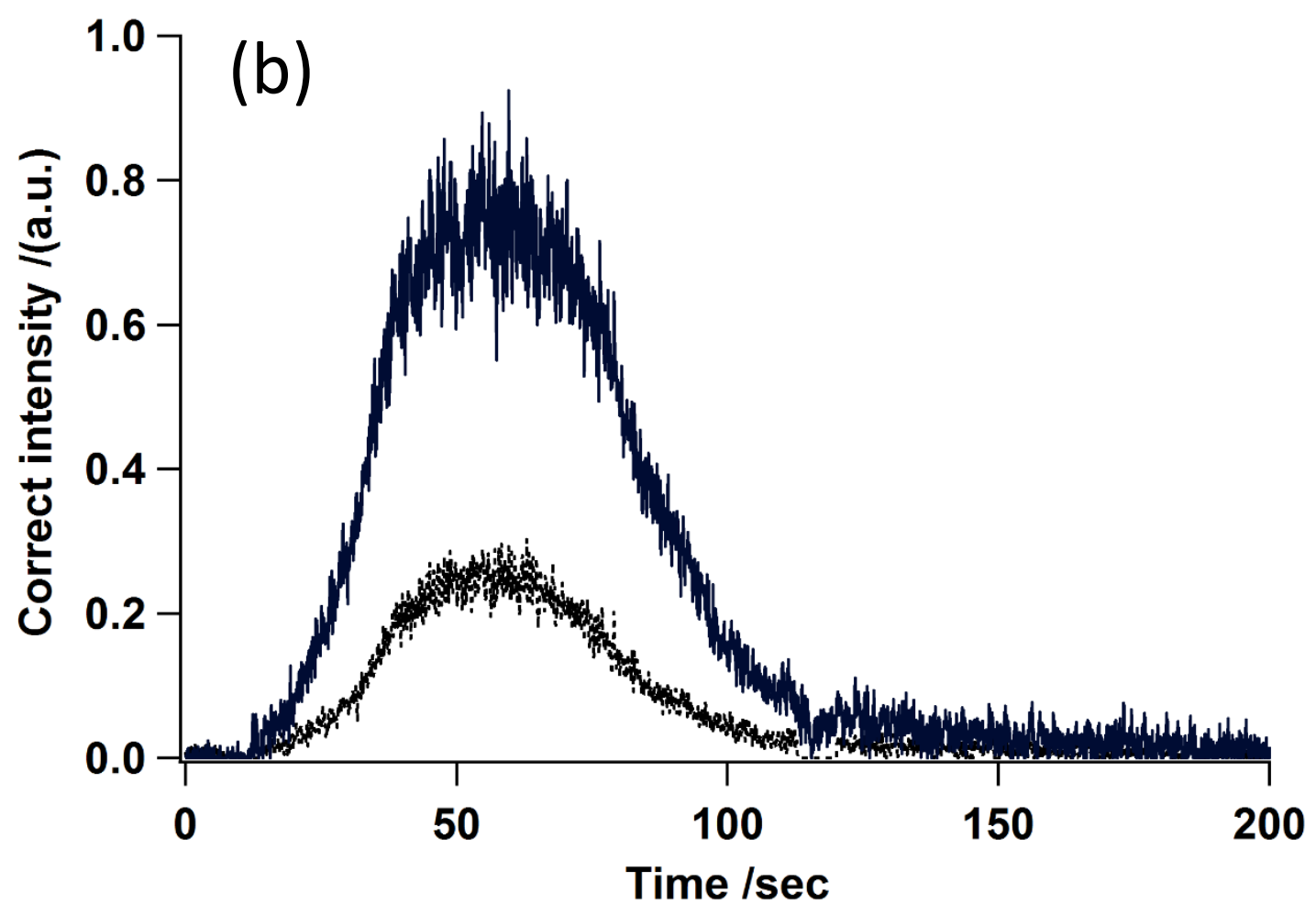


Fig. 5.

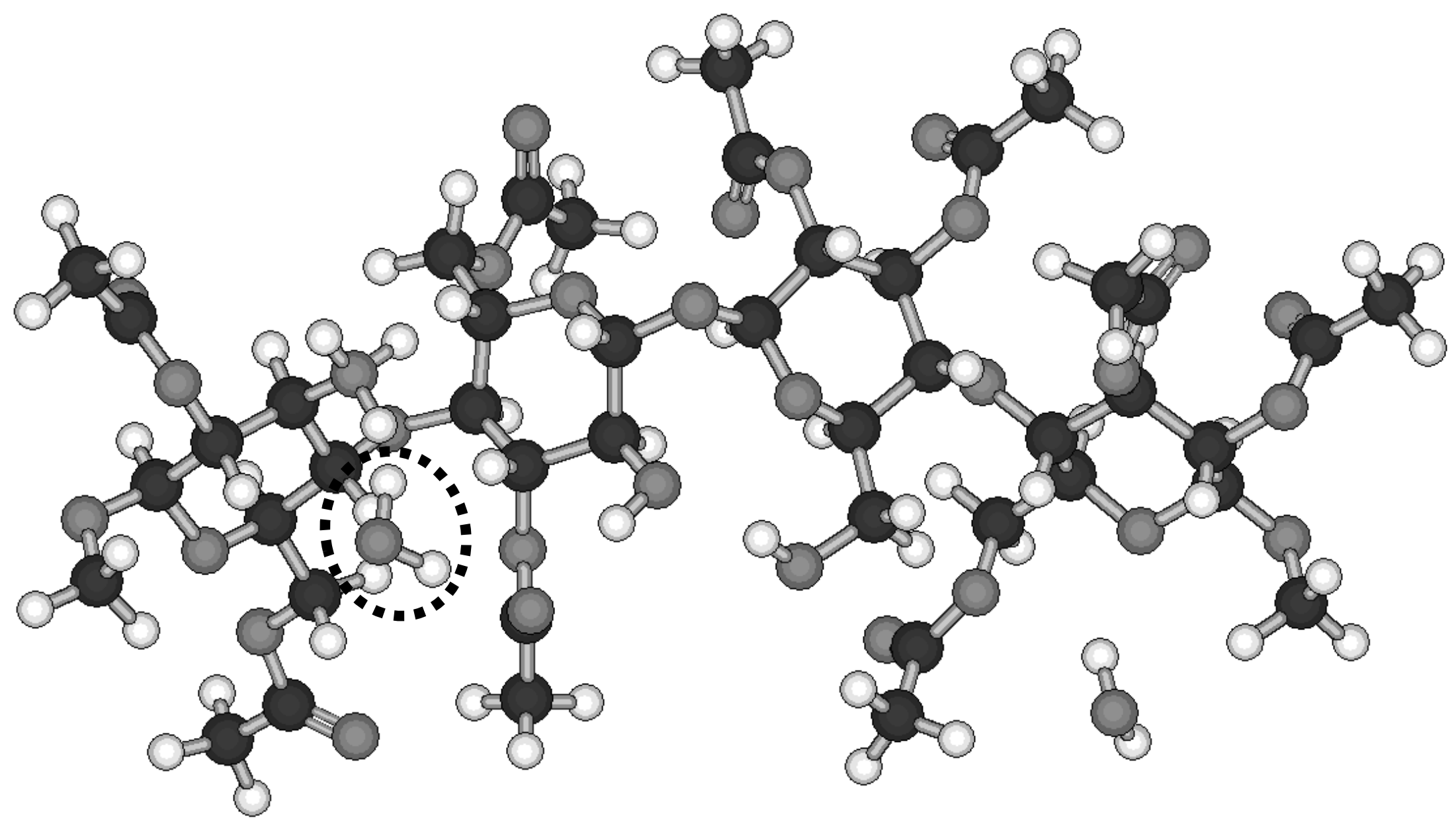


Fig. 6.
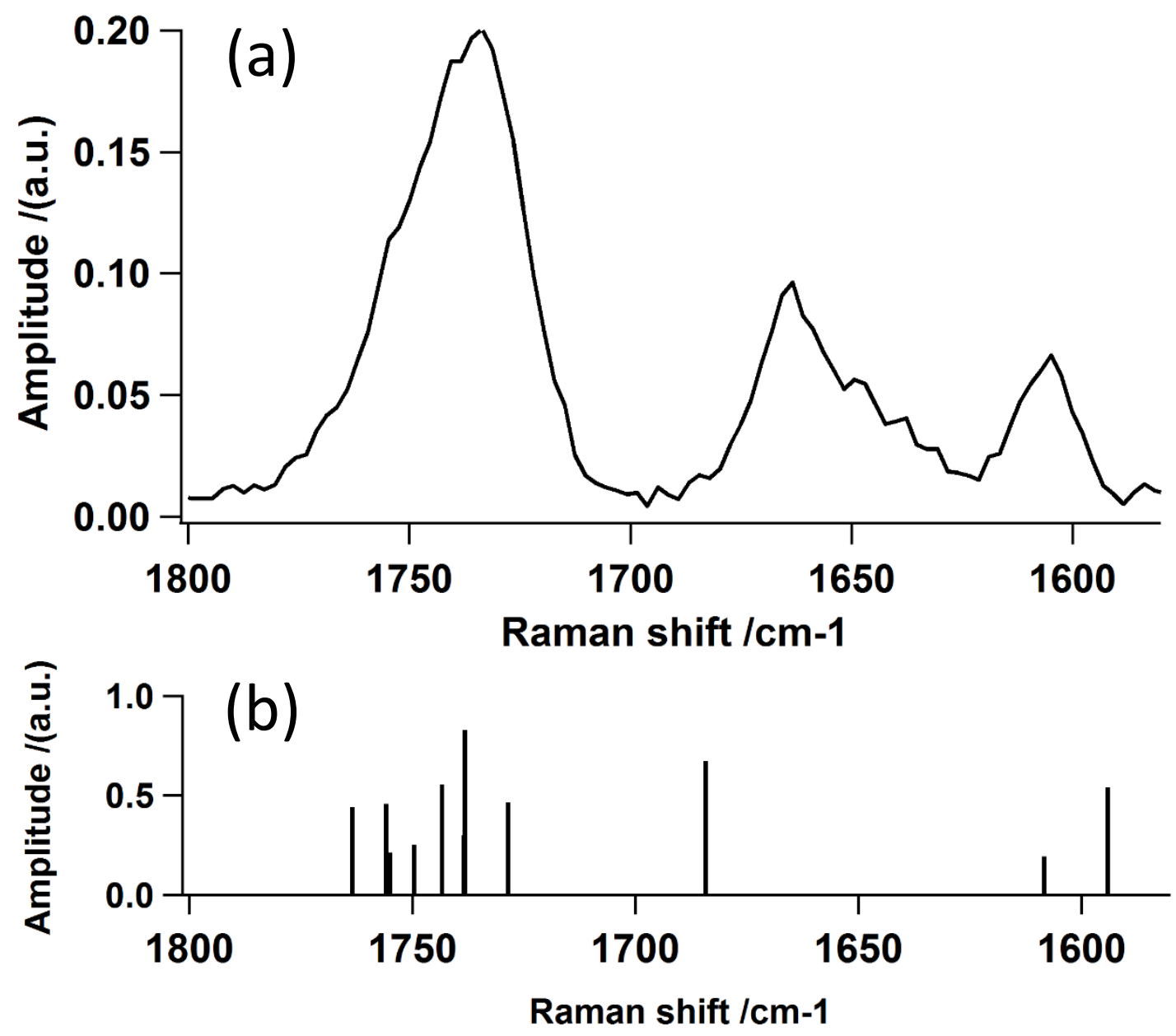